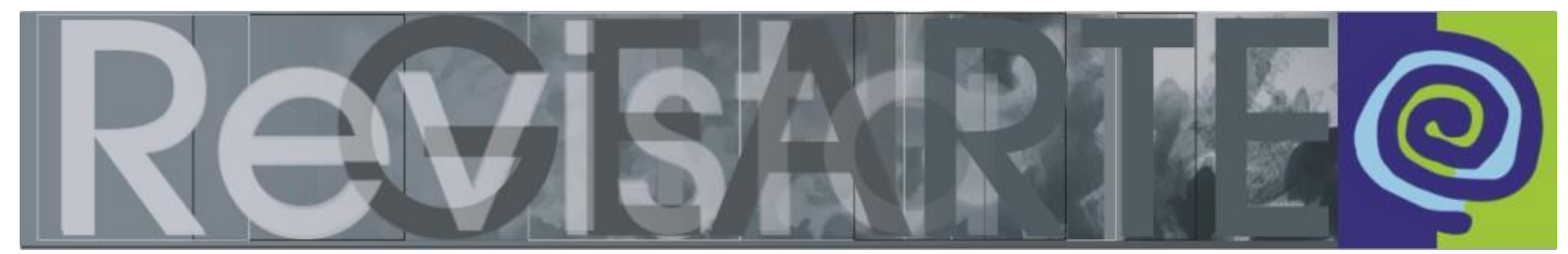

ISSN 2357-9854 | e-ISSN 2596-3198 (online)

\title{
Projeto CraftCabanyal: \\ ações participativas de craftivismo na construção de obras artísticas reivindicativas a partir da iconografia de um lugar
}

\author{
Fabiane Cristina Silva dos Santos \\ (Espai 241-LAB, Valência, Espanha)
}

\begin{abstract}
RESUMO - Projeto CraftCabanyal: ações participativas de craftivismo na construção de obras artísticas reivindicativas a partir da iconografia de um lugar - A partir do diálogo entre a arte e o artesanato observamos um crescimento de ações artísticas através de processos colaborativos a partir de lema "Faça você mesmo", surgindo assim ações artísticas de Craftvismo, movimento que parte do cruzamento entre o artesanal e o ativismo. Surge uma nova forma de se relacionar com o espaço público, potenciando um ativismo político através de novas estratégias para a produção artística, convertendo a criação em uma ação social integrada a diversas pessoas que vivem em um contexto determinado. Abordaremos algumas ações artísticas colaborativas e, especificamente, apresentamos o projeto artístico colaborativo CraftCabanyal, realizado na cidade de Valência, Espanha.
\end{abstract}

PALAVRAS-CHAVE

Craftvismo. Arte participativa. Espaço privado/público. CraftCabanyal. Iconografia.

ABSTRACT - CraftCabanyal Project: participatory craftivism actions in the construction of claiming artistic works from the iconography of a place - From the dialogue between art and handicrafts, we observed an increase in artistic actions through collaborative processes based on the motto «Do it yourself», thus creating artistic actions by Craftvismo, a movement that starts from the intersection between artisanal and activism. A new way of relating to the public space emerges, enhancing political activism through new strategies for artistic production, converting creation into a social action, integrating diverse people who live in a determined context. We will address some collaborative artistic actions and specifically, we present the collaborative artistic project CraftCabanyal, carried out in the city of Valencia, Spain.

KEYWORDS

Craftvism. Participatory Art. Private/public space. CraftCabanyal. Iconography.

RESUMEN - Proyecto CraftCabanyal: acciones de craftivismo participativo en la construcción de obras artísticas reivindicativas desde la iconografía de un lugar - A partir del diálogo entre el arte y la artesanía, observamos un crecimiento de acciones artísticas a través de procesos de colaborativos basadas en el lema «hazlo tú mismo", lo que resulta en acciones artísticas de Craftvismo, un movimiento que parte de la intersección entre lo artesanal y el activismo. Surge una nueva forma de relacionarse con el espacio público, mejorando el activismo político a través de nuevas estrategias para la producción artística, convirtiendo la creación en una acción social, integrando a diversas personas que viven en un contexto determinado. Abordaremos algunas acciones artísticas colaborativas y, específicamente, presentamos el proyecto artístico colaborativo CraftCabanyal, realizado en la ciudad de Valencia, España.

PALABRAS CLAVE

Craftvismo. Arte participativo. Espacio privado / público. CraftCabanyal. Iconografía. 


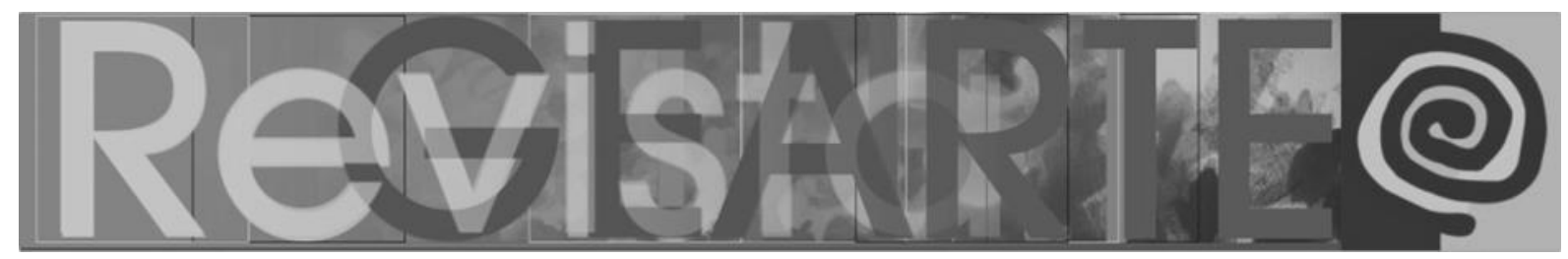

Eu definiria arte pública como qualquer tipo de trabalho livremente acessível que cuide, desafie, implique e leve em consideração a opinião do público por quem ou com quem foi feita, respeitando a comunidade e o meio ambiente. (LIPPARD, 2001, p. 61, tradução nossa)

A arte passa a ter uma função social com a mudança do paradigma estético e o surgimento de novas formas de expressão, fazendo uma chamada de atenção para colocar em evidência situações importantes. O espaço público passa a ser o local de intervenção, buscando a participação do público e o diálogo entre o espaço público e privado. Ao longo da história vários artistas trabalharam essa interação com o público, como a ação de Yoko Ono Cut piece [Corte um pedaço, 1964], Félix Gonzales-Torres - Montanha de doces embrulhados (Sem título,1991) ou os primeiros happenings de Allan Kaprow, que convidava aos espectadores a interagir com a obra.

\begin{abstract}
Ao longo dos séculos $\mathrm{XIX}$ e $\mathrm{XX}$, o artista ganhou um papel importante como agente de mudança social, baseado em discussões e ações de vanguarda em relação ao conteúdo político da arte. Ao deixar os museus e os espaços consagrados da cultura burguesa, passa a fazer parte da vida popular devido à sua relação com o espaço e seus problemas. A partir da década de 1980, acentuou-se a relação entre arte e política, multiplicando as iniciativas artísticas por meio das quais os artistas procuravam promover a participação de pessoas do público em projetos como a experimentação de formas de socialização e ocupação de espaços locais etc. (SILVA DOS SANTOS, 2015, p. 444, tradução nossa)
\end{abstract}

Nos últimos anos vários artistas vêm desenvolvendo trabalhos no campo da arte participativa, com ações colaborativas através do movimento do Craftvismo, um cruzamento entre 0 artesanal e o ativismo. Atualmente, devido às transformações sociais que estamos assistindo, observamos uma mudança de paradigma nas relações sociais e políticas, com grandes ações no desenvolvimento social a partir da coesão social com a arte, fruto do trabalho de participação, colaboração e coletividade. A arte entra como veículo para promover a coesão social, criando um trabalho criativo, transformando ou visibilizando uma problemática e gerando espaços de resistências. "O espaço e o tempo tornaramse domésticos, mansos como o animal que pode coabitar nos aposentos e os hábitos de seus habitantes" (ECHEVERRÍA, 2003, p. 23, tradução nossa). 


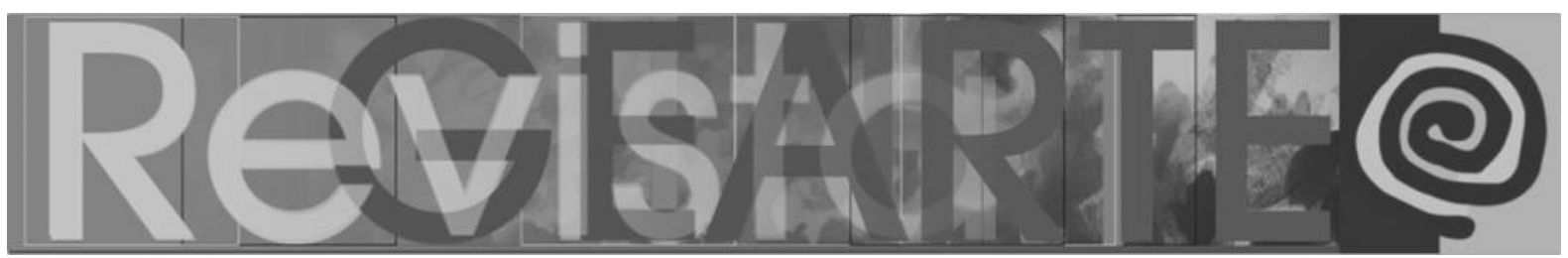

Muitos coletivos utilizam o processo colaborativo para desenvolver ações artísticas, utilizando atividades que em geral são desenvolvidas na espera privada e atuando na esfera pública como forma de resistência para dar visibilidade a certas problemáticas. Podemos citar exemplos de ação que vêm se desenvolvendo em diferentes lugares do mundo, como o projeto Crochet Coral em Chicago, que teve início em 2015 e que, através do crochê, utiliza o plástico do lixo junto com a lã para criar arrecifes gerando um ambiente marinho para protestar contra o aquecimento global. Em 2005 na cidade de Houston, inicia-se o movimento a partir do qual os monumentos aparecem decorados com tricô e crochê, ganhando seguidores em todo o mundo e na Espanha, nas cidades de Barcelona, Bilbao e Valência, o que gerou uma rede chamada Urban Knitting. O fenômeno atingiu várias cidades do norte ao sul do país e consiste em uma ação em prol de uma causa. A partir de reuniões semanais, promove-se ações que reivindicam o fazer manual. Os conceitos de socialização, reciclagem e igualdade passam a ser a chave de seus princípios.

\begin{abstract}
A arte colaborativa, portanto, busca rever o papel do artista, do público e da obra, questionando a concepção tradicional de arte. O artista é colocado em pé de igualdade com o espectador, e deixa de ser o destinatário passivo e torna-se ativamente integrado ao processo de desenvolvimento do trabalho. $O$ trabalho também recebe uma nova percepção, que surge em relação ao seu contexto, e o processo ganha importância a partir do conjunto de seus atores e de suas ações: o trabalho resultante deixa de ser um objetivo e se torna evidência direta que apresenta resultado da multiplicidade de ações criativas individuais. Nesse processo de desenvolvimento da proposta, para que seu objetivo seja alcançado, é importante que todos participem da elaboração do projeto. Isso gera uma metodologia para que, em geral, todos os participantes se relacionem, promovendo a integração de diferentes grupos que coexistem em um determinado contexto social. (SILVA DOS SANTOS, 2015, p. 446, tradução nossa)
\end{abstract}

Durante muito tempo a sociedade cultivou uma lógica social individualista, na qual nosso círculo de relações se concentrava na família e nos amigos próximos, e a casa era o espaço privado, o refúgio contra os elementos externos. Atualmente, estamos alcançando grandes mudanças sociais a partir da colaboração, da participação e da coletividade. Uma das ferramentas utilizadas para conseguir essa 


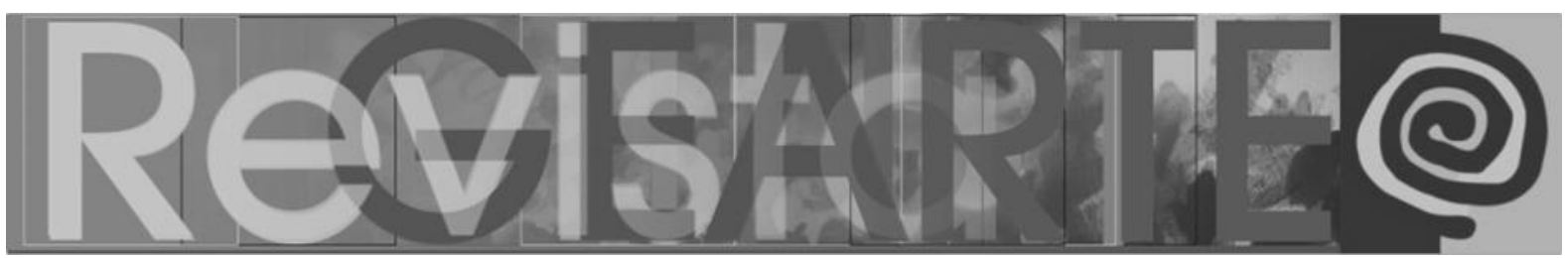

coesão social é a arte, que vem gerando trabalhos criativos e coletivos para viabilizar ou transformar um problema, gerando espaços de resistências.

Aqui vamos centrar nossa atenção ao projeto intitulado CrafCabanyal, realizado na cidade de Valência, na Espanha. O projeto surge das atividades da $15^{\mathrm{a}}$ edição de Cabanyal Portes Obertes ${ }^{1}$ em virtude do problema urbanístico que afetava o bairro do Cabanyal-Canyamelar e que consistia no projeto de demolição de 1.651 casas, algumas delas com importante valor arquitetônico, dividindo o bairro em duas partes, o que supunha o fim desse bairro tal como o conhecemos. Esse projeto municipal levou a uma paulatina degradação da estrutura do bairro e encontrou importante oposição da sociedade civil, organizada por coletivos e associações, como a Plataforma Salvem el Cabanyal e a Associação de vizinhos do Cabanyal-Canyamelar, entre outras. Nos últimos vinte anos, essas associações conseguiram a paralisação do projeto municipal, dando a conhecer esta situação no exterior e convertendo-o em um caso de estudo a nível nacional e internacional. Neste caso é importante deixar em evidência que o evento cultural de Portes Obertes se mostrou muito útil frente à imposição mediática e à exclusão proposta pelo poder político hegemônico, que patrocinou o projeto de destruição do bairro.

CraftCabanyal ${ }^{2}$ surge dentro deste contexto do bairro do CabanyalCanyamelar, uma proposta da Plataforma Salvem el Cabanyal ${ }^{3}$, que é um projeto de arte participativa do Craftvismo com perspectiva de gênero e intervenção/mediação cultural através da arte iniciado em 2013 e finalizado em 2018.

Seus objetivos foram:

- Realizar uma ação de arte colaborativa na qual os vizinhos se relacionam e compartilham suas experiências, dando visibilidade ao seu entorno;

- Utilizar as ferramentas da arte como veículo para o diálogo entre os espaços público e privado a partir de uma perspectiva de gênero baseada na igualdade; 


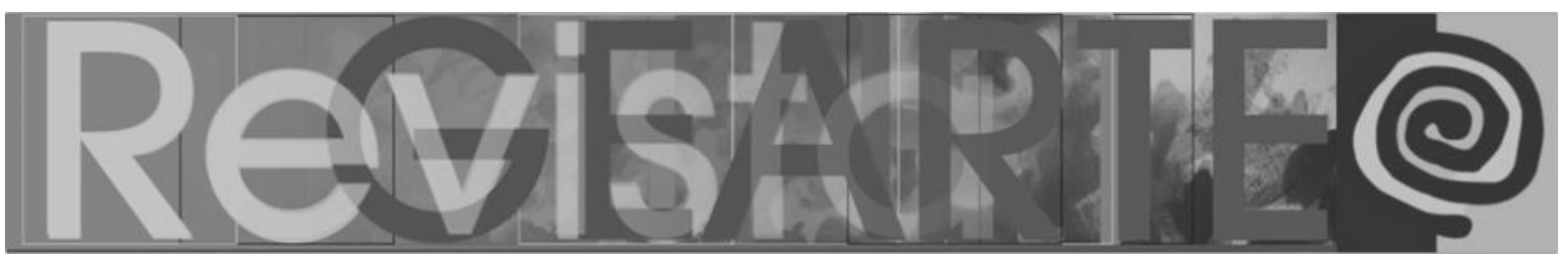

- Relacionar-se com associações e instituições educacionais locais;

- Trocar experiências entre artistas e participantes;

- Realizar um trabalho de mediação social, gerando espaços de diálogo e integração entre vizinhos de diferentes gerações, gerando um espaço de resistência, para transformar ou tornar visível um contexto ou um problema;

- Trabalhar a autoestima dos moradores do bairro através do envolvimento com base em suas experiências como um valor intocável em torno de sua herança tangível e intangível;

- Organizar uma série de oficinas participativas e colaborativas, como uma maneira dinâmica no contexto local, a partir da compreensão e respeito por seus valores culturais e patrimoniais;

- Utilizar as novas tecnologias como ferramenta de suporte para fortalecer as ações, na sua divulgação e registro.

A partir destes objetivos, realizamos cinco ações - intervenções artísticas no artivismo, com a colaboração de vizinhos, amigos e pessoas que apoiam a luta do bairro e que tiveram a oportunidade de expressar sua visão do bairro a partir do processo criativo e, ao mesmo tempo, participar de um trabalho artístico em defesa do patrimônio material e imaterial, através de um trabalho coletivo e colaborativo, utilizando os valores dos trabalhos realizados em geral na esfera privada, como o bordado, o crochê, patchwork, trabalhos manuais etc. Por meio da ação artesanal, os moradores do bairro e participantes do projeto são coautores de um trabalho participativo. Trabalhamos com a autoestima dos moradores do bairro, através do envolvimento e de experiências que são um valor intangível de suas heranças e memórias.

As primeiras obras realizadas foram Fet a mà :: El ir y venir de las agujas en el Cabanyal (Figura1), em que se realizou uma série de intervenções nas casas 


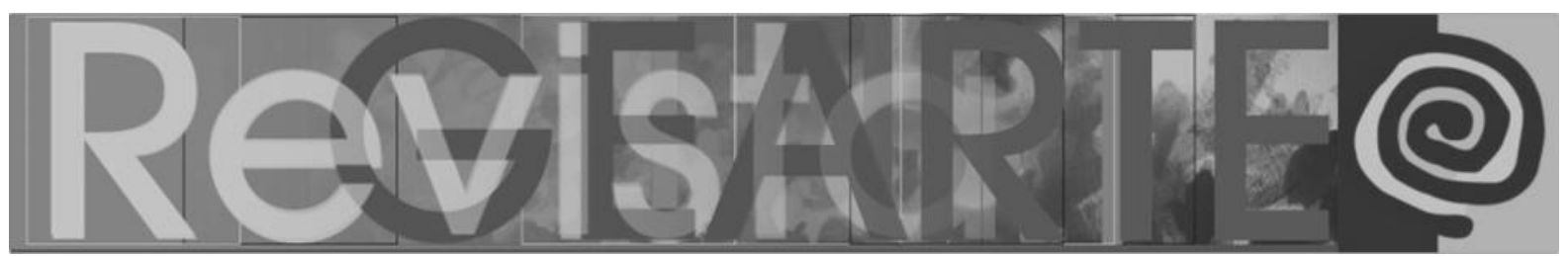

fechadas pela prefeitura da cidade em uma das ruas mais degradada do bairro. As obras foram realizadas em tecidos que foram colocados no lugar das portas que já não existem.

Figura 1 - Fet a mà :: El ir y venir de las agujas en el Cabanyal

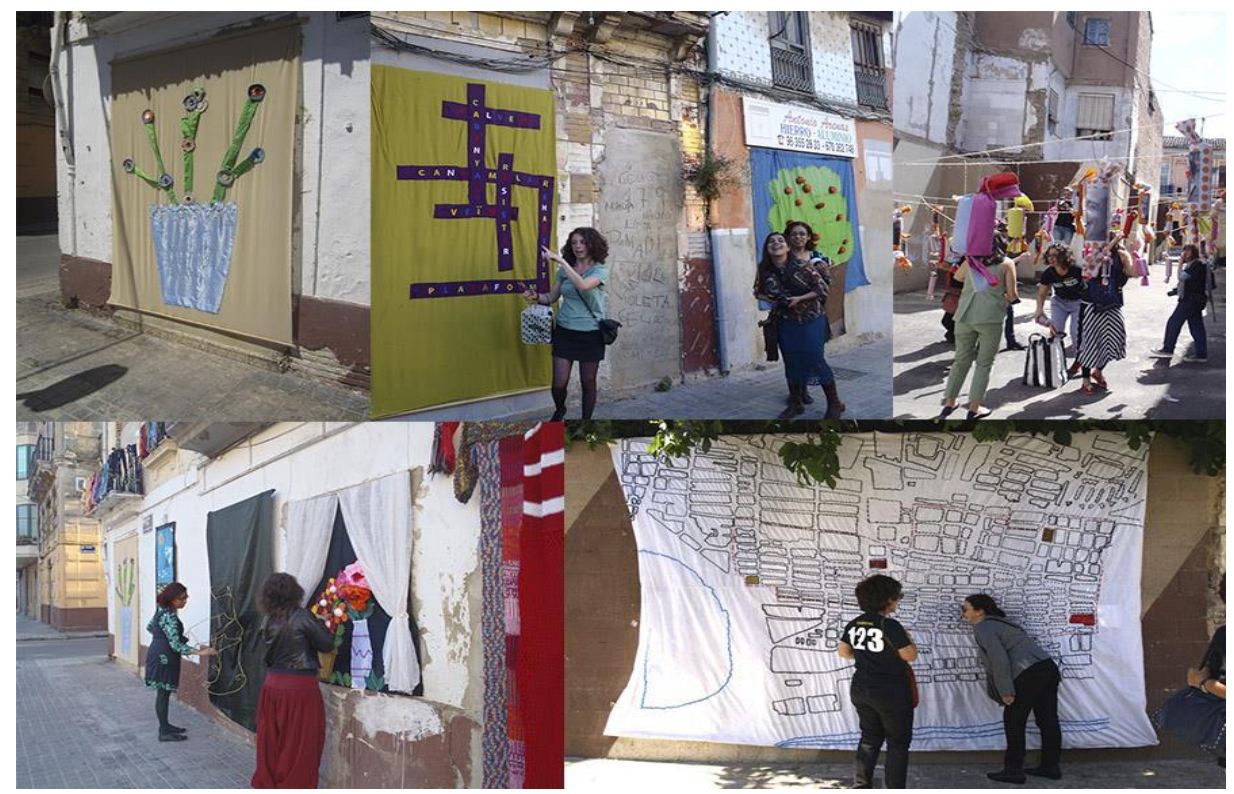

Fonte: Foto de arquivo do projeto CraftCabanyal in: http://www.espai214.org/craftcabanyalproyectos/

Figura 2 - Què pasa aci?
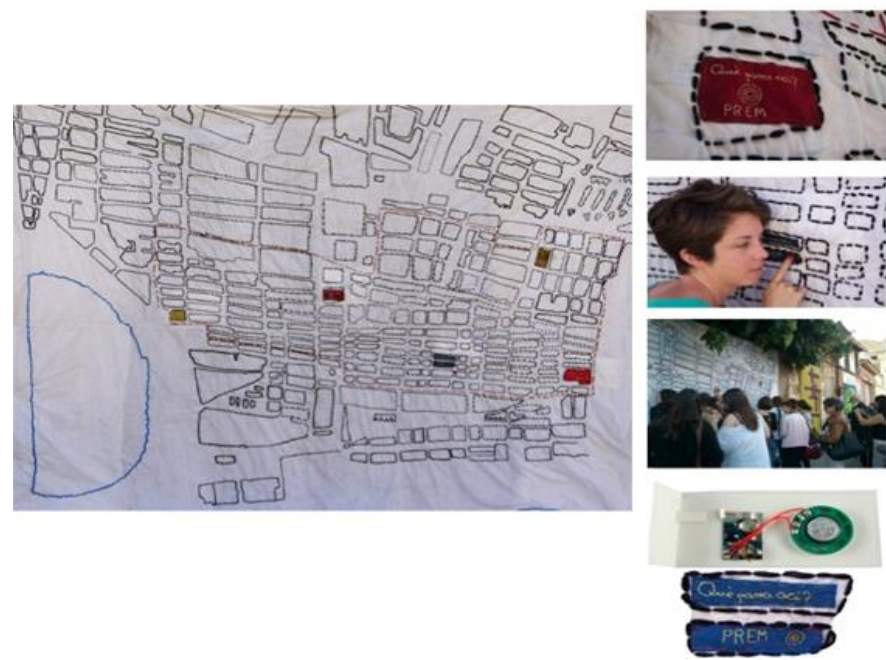

Fonte: Foto de arquivo do projeto CraftCabanyal in: http://www.espai214.org/craftcabanyalproyectos/ 


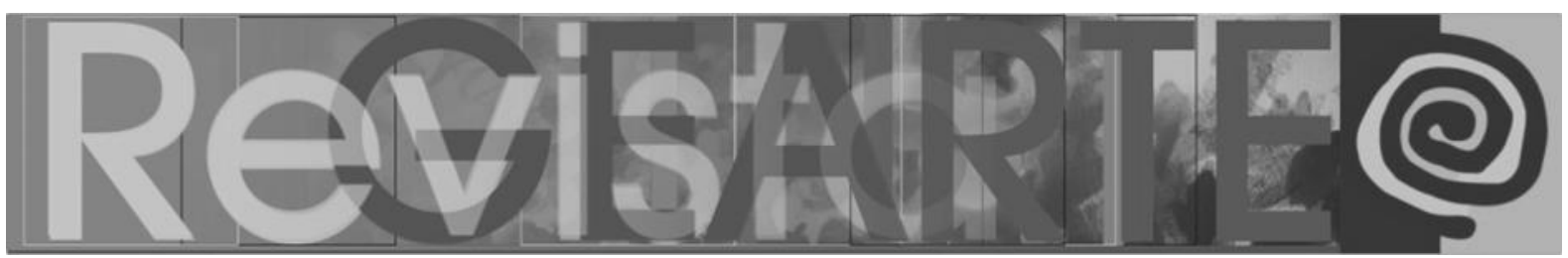

Aqui vamos destacar a obra Què pasa acì?_(Figura 2), um grande bordado do mapa do bairro de $4 \times 5,5 \mathrm{~m}$. No traçado se delimita o que está declarado como bem de interesse cultural. Dentro desse traçado estão implantados chips com áudios em que se pode escutar declarações de moradores locais sobre o bairro.

Essa obra foi plasmada na rede, convertendo-se em uma web art (Figura 3) em um processo de interação ampliada em que se escuta e em que se pode deixar registrada a impressão dos visitantes sobre o bairro do Cabanyal. Utilizando os elementos da obra como interface para a web, em uma espécie de jogo, "pontos quentes" são sinalizados através do mouse como hiperlinks que levam à narração das declarações. São cinco declarações que falam sobre diferentes visões, como recordações da infância, de quando brincavam na rua ou quando passava o carro de venda do peixe; ou de onde viveram e o que faziam até os dias de hoje; como é visto o bairro através da visão dos novos moradores ou vizinhos de outros bairros; e, por fim, de que maneira reagem contra o plano urbanístico da prefeitura de Valência.

Figura 3 - Què passa ací?

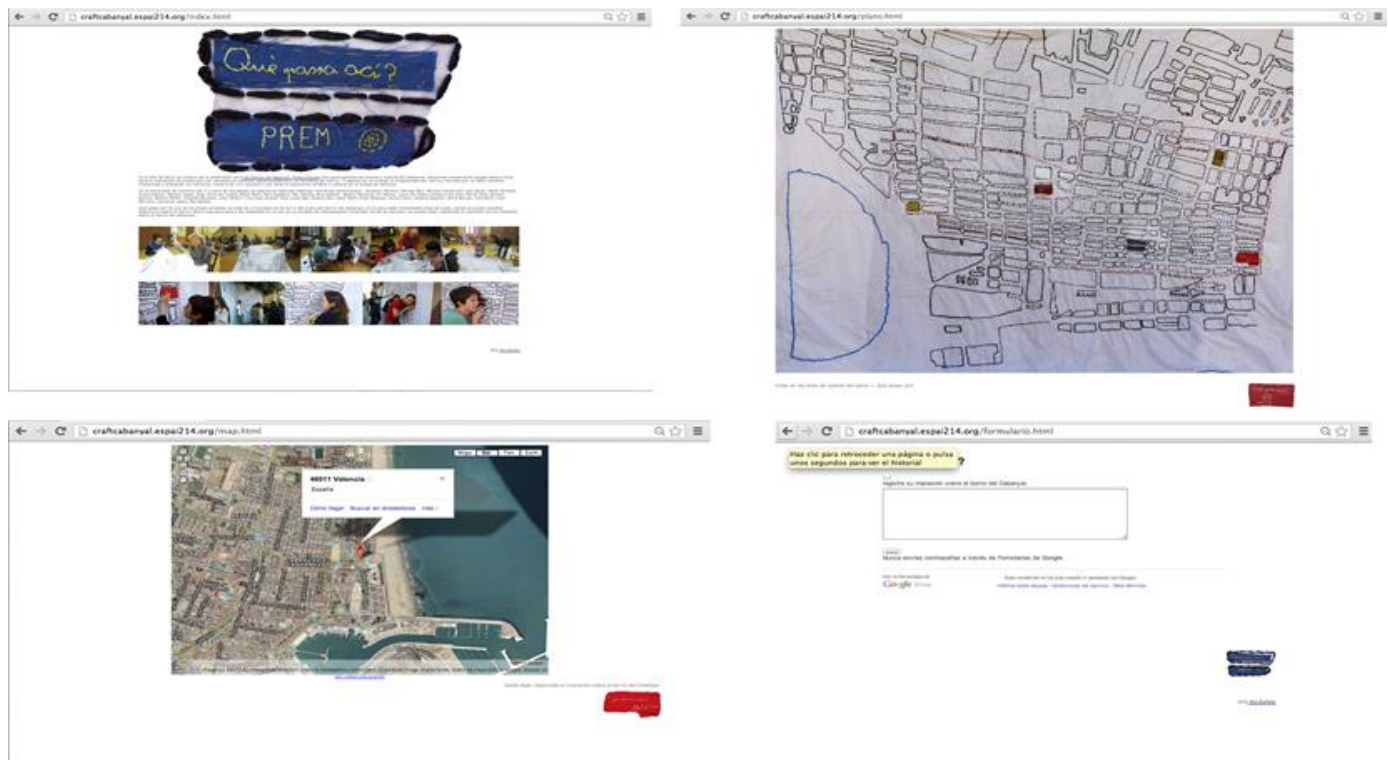

Fonte: http://espai214.org/craftcabanyal/quepassaasi.html 


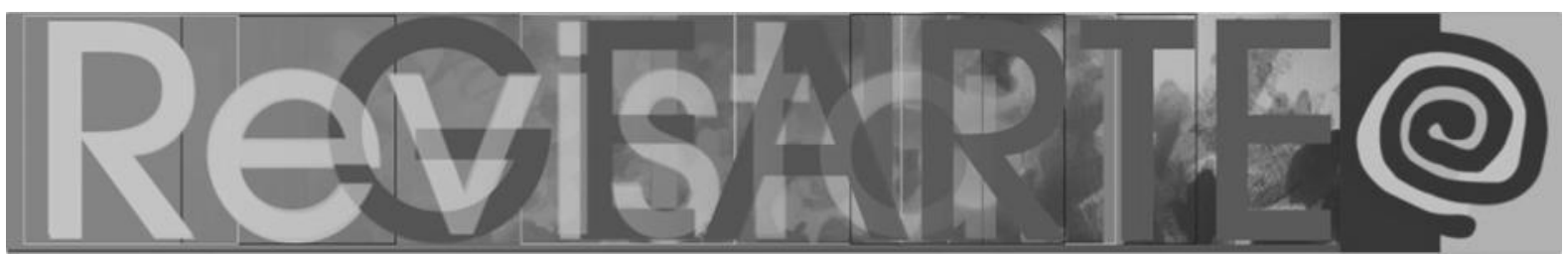

Realizamos em 2014 o Cabanyal t'estime: rehabilitació sense destrucció (Figura 4), em que produzimos trezentos cartões com um recorte tridimensional de um coração. Eles também continham a imagem da fachada de uma casa no bairro e a frase "Cabanyal t'estime". Eles foram distribuídos pelas caixas de correio do bairro para indicar a importância da participação de todos os vizinhos na reabilitação do Cabanyal.

Figura 4-Cabanyal t'estime: rehabilitació sense destrucció

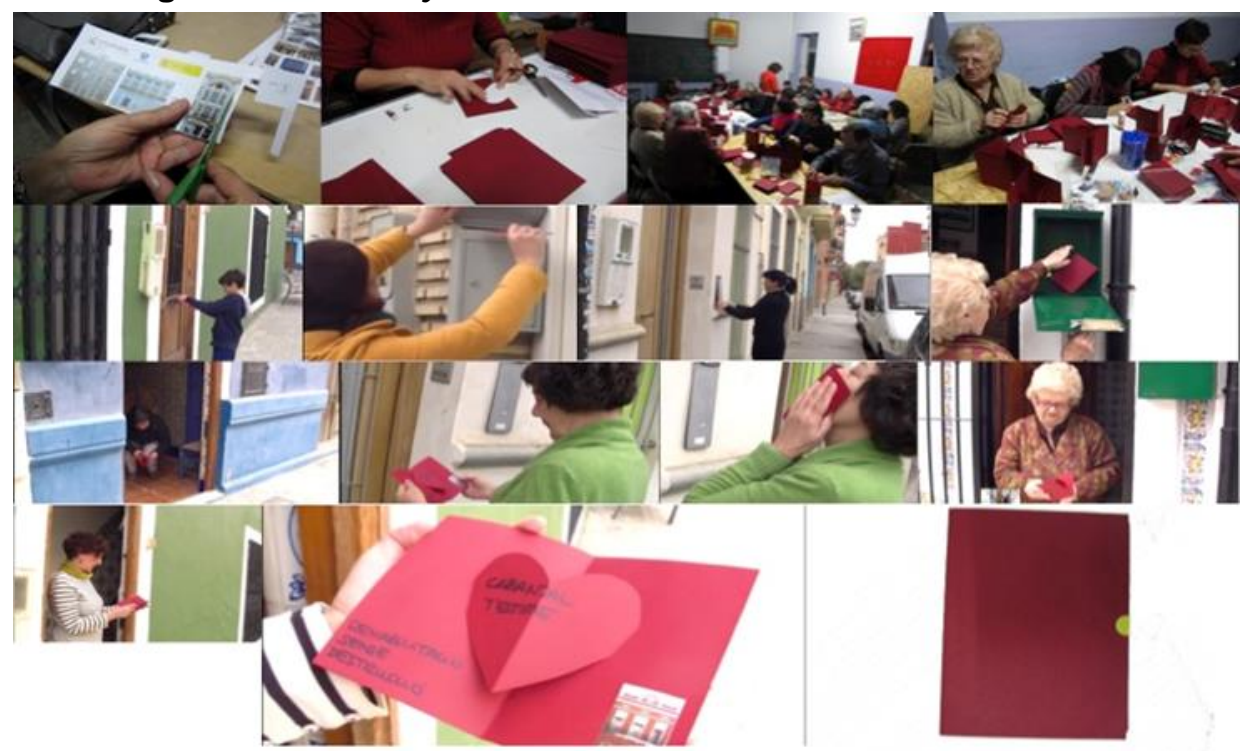

Fonte: Foto de arquivo do projeto CraftCabanyal in: http://www.espai214.org/craftcabanyalproyectos/

Para o Cabanyal Portes Obertes de 2014, realizamos o projeto El Cabanyal punto a punto: distintas miradas Ilustrada, em que realizamos um trabalho coletivo através de uma convocatória aberta à comunidade local para desenvolver uma série de oito livros de tecido com tamanho de $50 \times 70 \mathrm{~cm}$ por página, tendo como referência o Cabanyal e refletindo suas memórias, costumes e tradições. Cada participante realizou duas páginas do livro, ilustrando artesanalmente, em uma tela branca de setenta centímetros de largura por cinquenta de altura. No livro são incrustrado chips de áudio e marcas QR. Participaram mais de cem pessoas de várias gerações, tantos vizinhos do bairro como de outras cidades e outros países. 


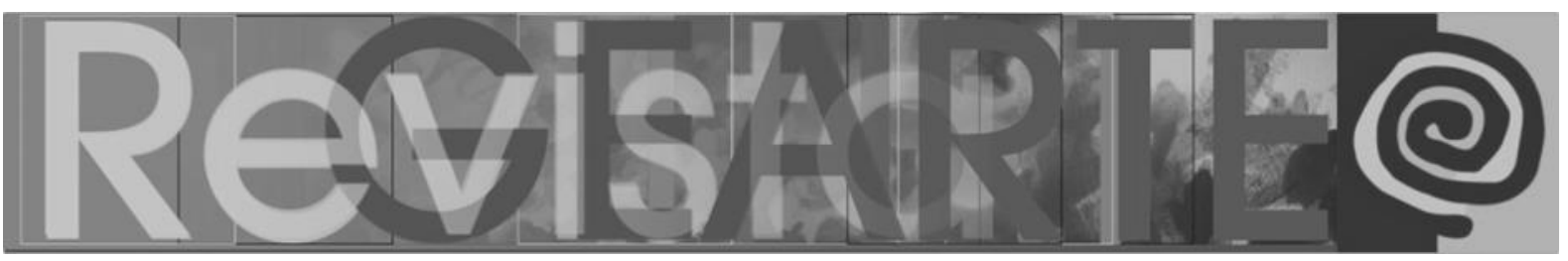

Figura 5 - Projeto El Cabanyal punto a punto: distintas miradas Ilustrada

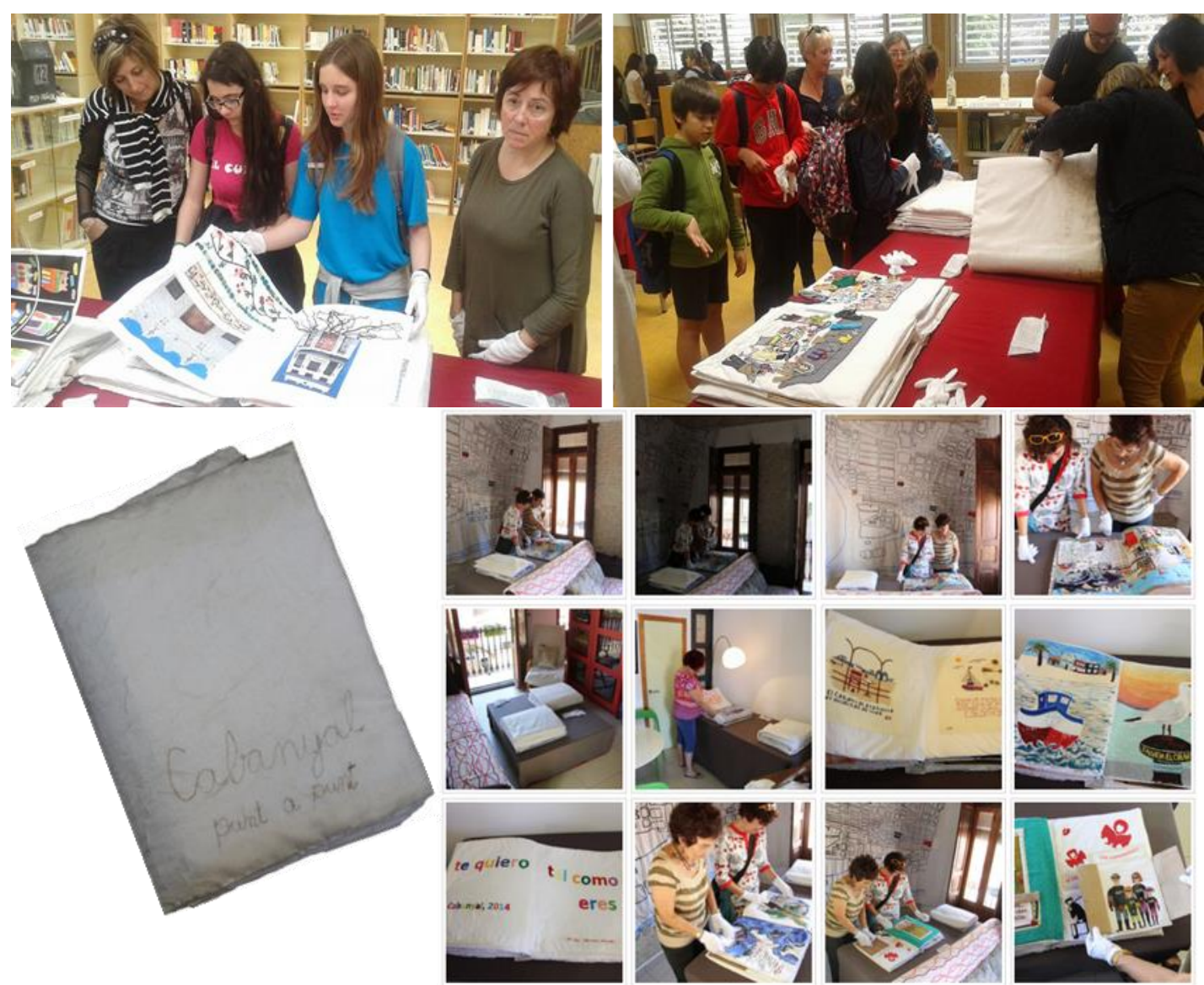

Fonte: Foto de arquivo do projeto CraftCabanyal in: http://www.espai214.org/craftcabanyalproyectos/

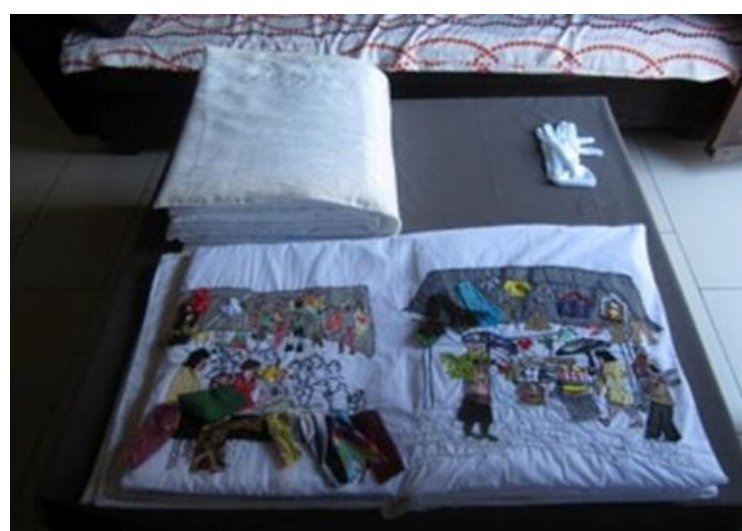

Exposição dos libros - Página realizada por: Maria Joilda dos Santos

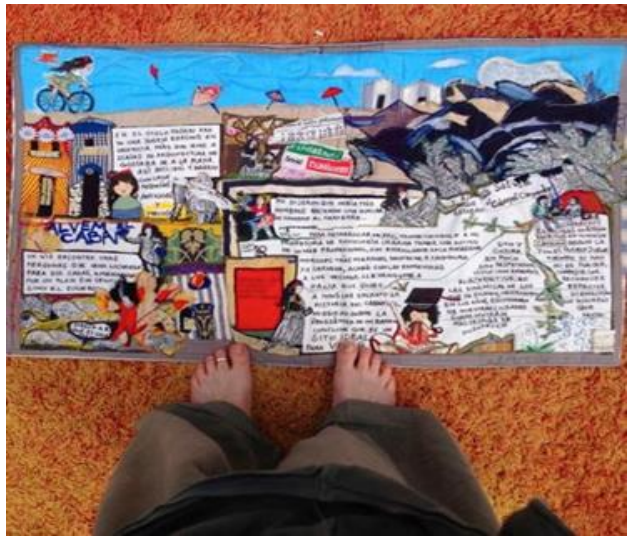

Página realizada por: Veronica della Rocca 

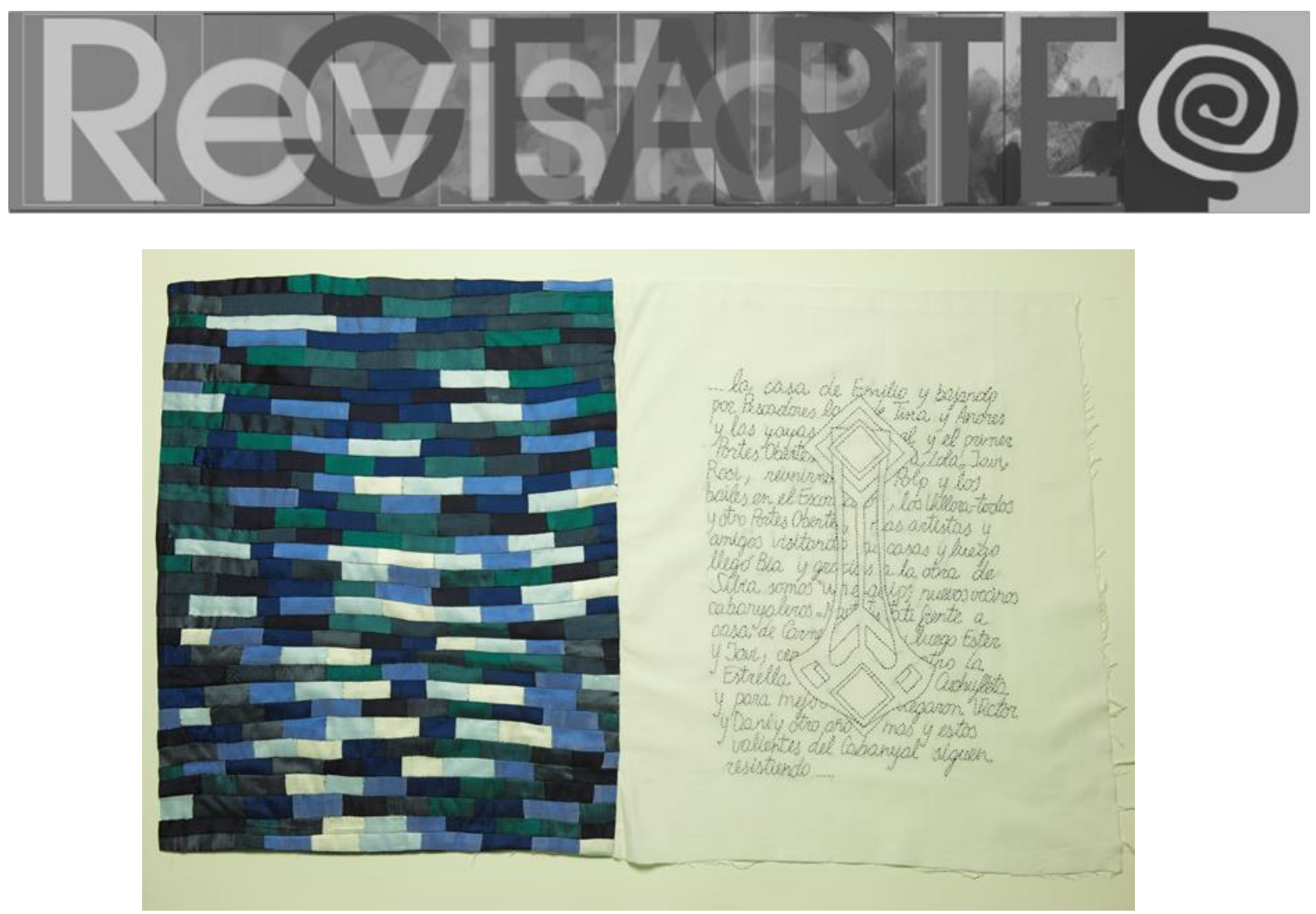

Página do livro realizada pela artista Lidon Artero Fonte: Foto de arquivo do projeto CraftCabanyal in: http://www.espai214.org/craftcabanyalproyectos/

Em 2015 começamos o projeto \#CraftCabanyal: bordando la Orden Ministerial CUL/3631/2009, de 29 de diciembre, para su cumplimiento (Figura 6), a partir do BOE que foi emitido em 2009 pelo Ministério de Cultura e que paralisou os derrubamentos das casa e protegeu o bairro. Decidimos bordar as dezessete páginas do BOE (cada página tem 1,5 $\mathrm{m} \times 2 \mathrm{~mm}$ ), bordando de forma coletiva e letra por letra 6.681 palavras e 35.821 caracteres. Participaram mais de quinhentas pessoas de vários lugares do mundo, como sinal de reconhecimento à ordem ministerial, que protegeu o patrimônio do bairro Cabanyal-Canyamelar-Cap de França. Trata-se de uma homenagem à ordem ministerial e, ao mesmo tempo, de uma ação que exige seu cumprimento, bem como a necessidade de solicitar iniciativas da atual equipe do governo que nos permita ver sinais de recuperação através de ações públicas, iniciando assim um compromisso de todos com a revitalização do bairro para permitir, acima de tudo, que os moradores recuperem as dignas condições de vida que perderam, principalmente nas áreas mais afetadas pela degradação. 


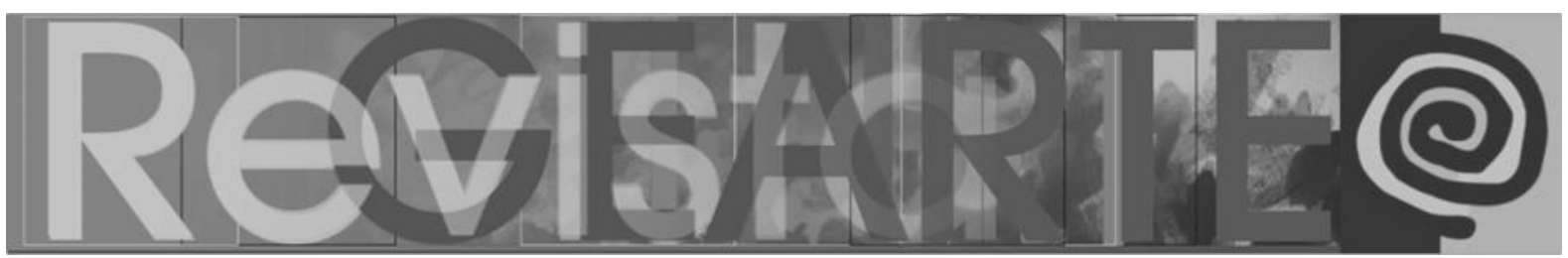

Figura 6 - «\#CraftCabanyal: bordando la Orden Ministerial CUL/3631/2009

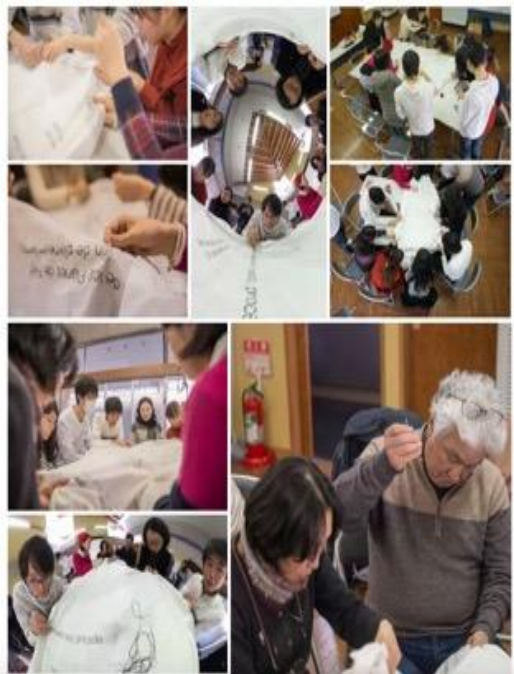

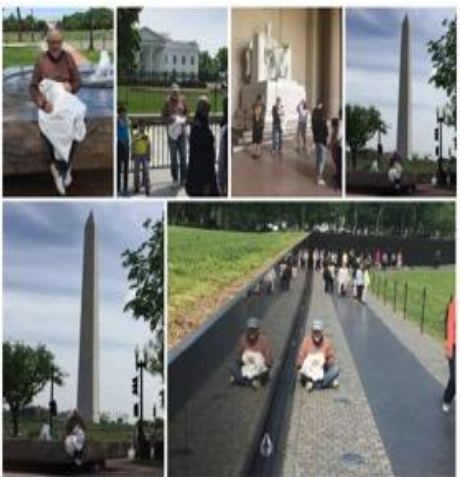

Bordando em Washington D.C. a página treze da ordem ministerial CUL/3631/2009.
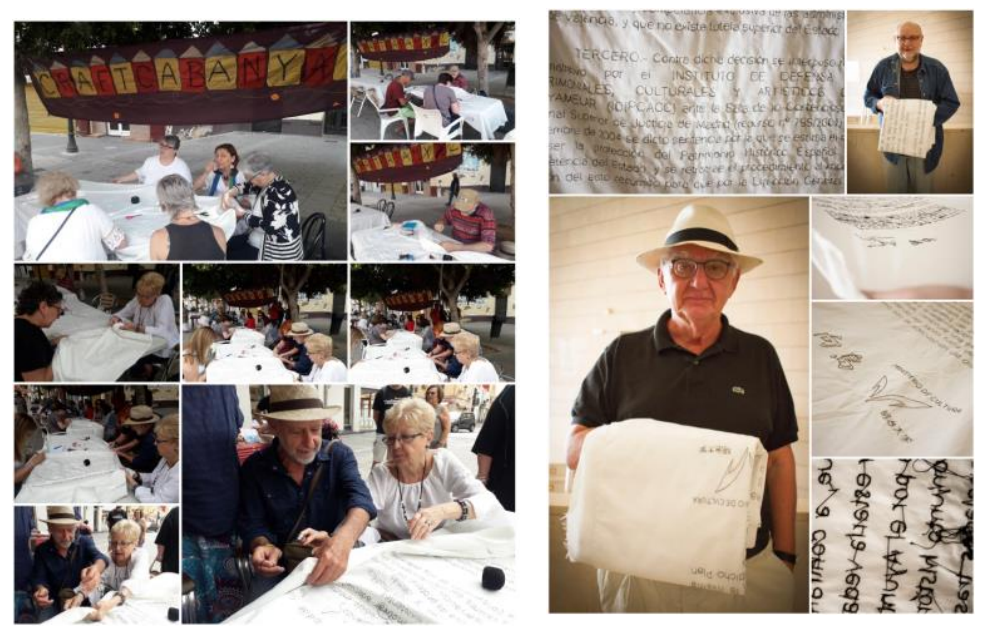

Bordando em Mukojima a página cinco da ordem Ministerial CUL/3631/2009.

\#CraftCabanyal: bordando la Orden Ministerial CUL/3631/2009, de 29 de diciembre, para su cumplimiento.

Fonte: Foto de arquivo do projeto CraftCabanyal in:

http://www.espai214.org/craftcabanyalproyectos/

As peças realizadas no projeto CraftCabanyal participaram de diferentes eventos de arte além do Cabanyal Portes Obertes, como, por exemplo, na exposição: Trazo Urbano VLC - Sala de exposiciones Josep Renau; Facultat de Belles Arts de Sant Carles - UPV (Figura 7), exposição Trama activa no museu Caravati, na Argentina (Figura 8), Festival de arte urbano Intramus, Ciudad Vella Oberta. Em 2017, elas participaram da exposição Testigos de la ciudad. activismos políticos y culturales en la comunidad Valenciana, no IVAM, Museu de Arte 


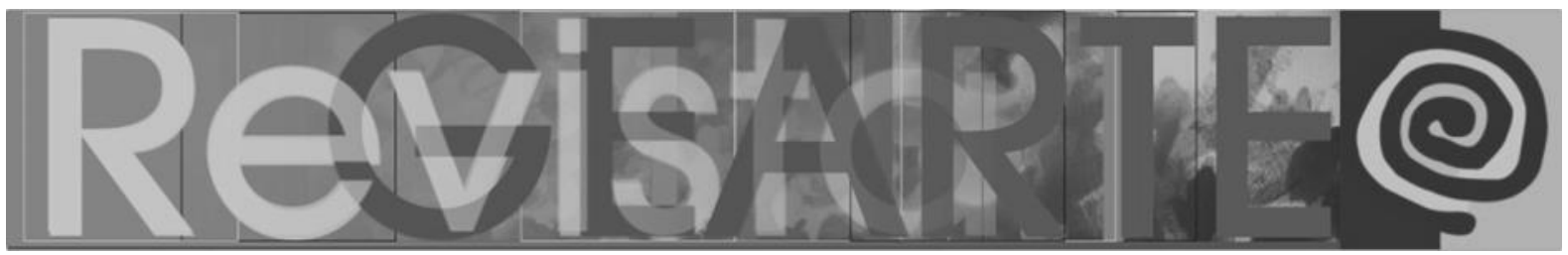

Moderna de Valência, assim como das manifestações reivindicativas tanto do bairro (Figura 9) quanto, por exemplo, de 8 de março (Figura 10) e do Dia internacional da Mulher Trabalhadora. $O$ projeto teve grande receptividade do público e dos meios de comunicação, e as redes sociais foram uma ferramenta crucial para promover essas ações.

Com a finalização das atividades da Plataforma Salvem El Cabanyal em 8 de junho de 2019, o projeto CraftCabanyal deu por encerrado suas ações.

Figura 7 - Exposición Trazo Urbano VLC
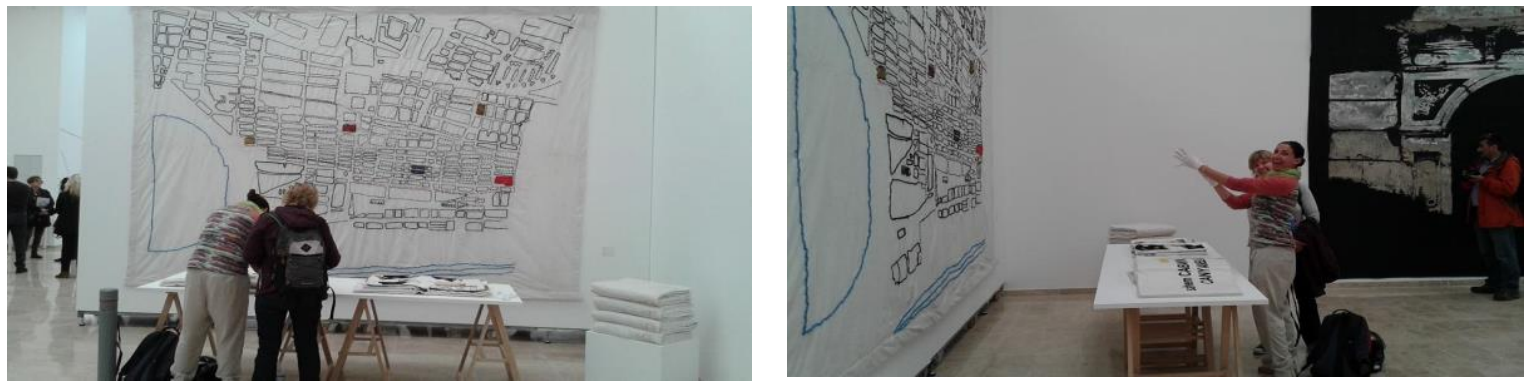

Fonte: Sala de exposiciones Josep Renau, Facultat de Belles Arts de Sant Carles - UPV.

Figura 8 - Trama Activa no museu Caravati, na Argentina

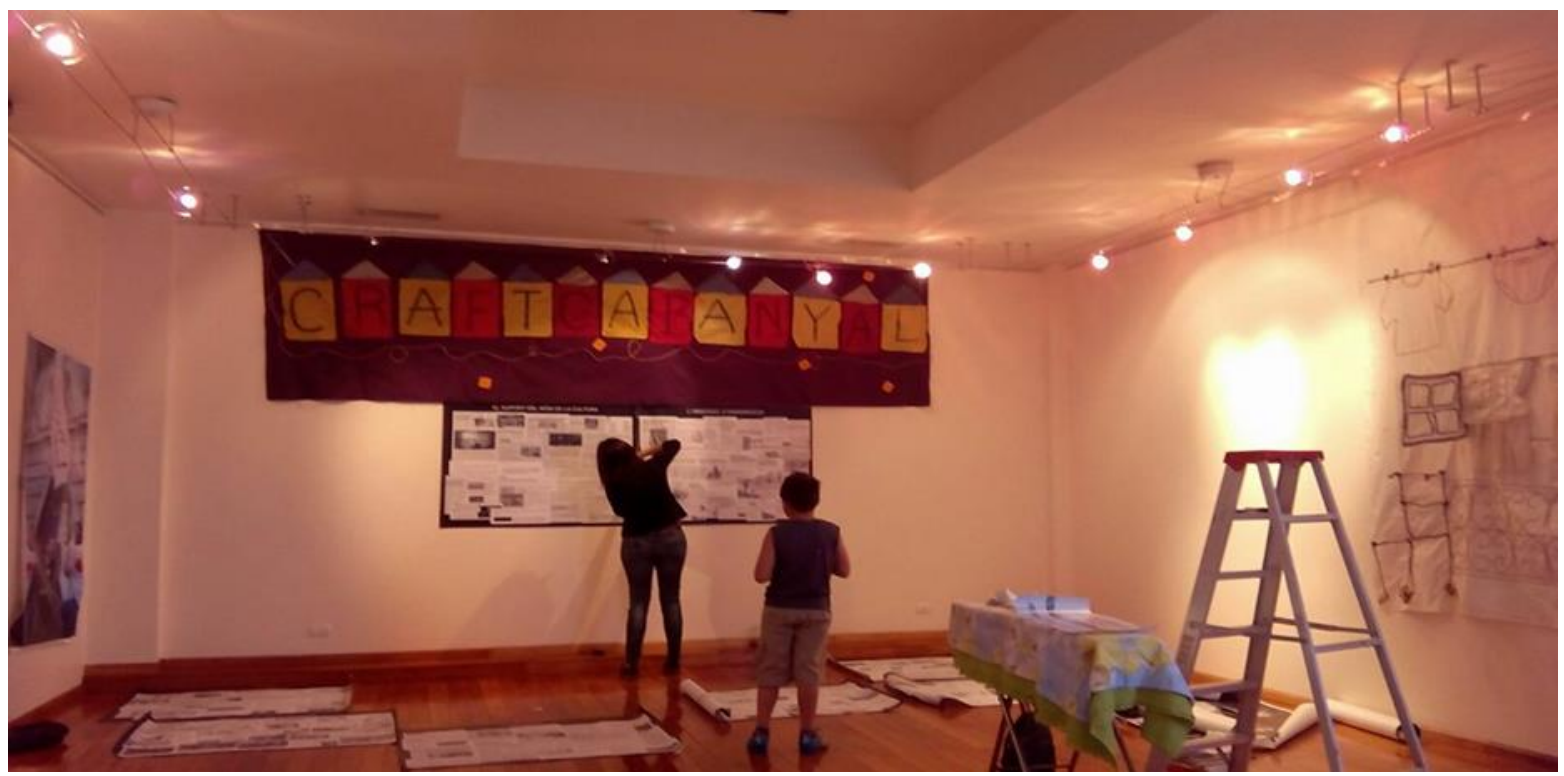

Fonte: Foto de arquivo do projeto CraftCabanyal in: http://www.espai214.org/craftcabanyalproyectos/ 


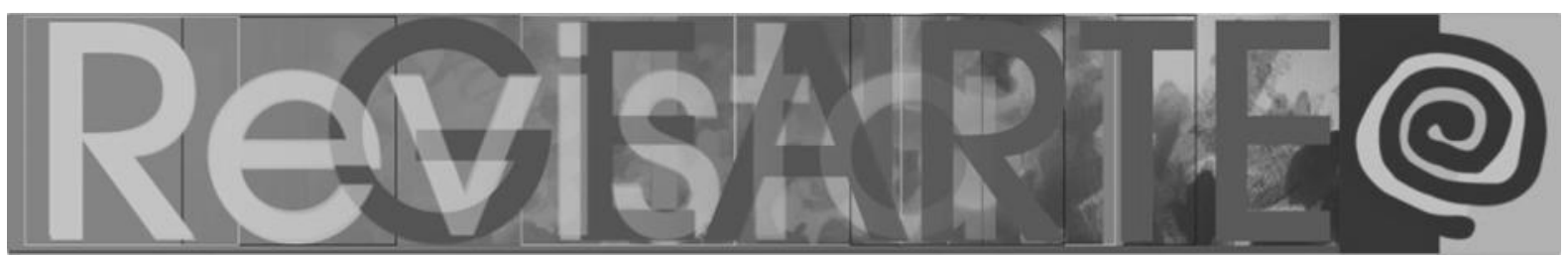

Figura 9-Manifestações reivindicativas
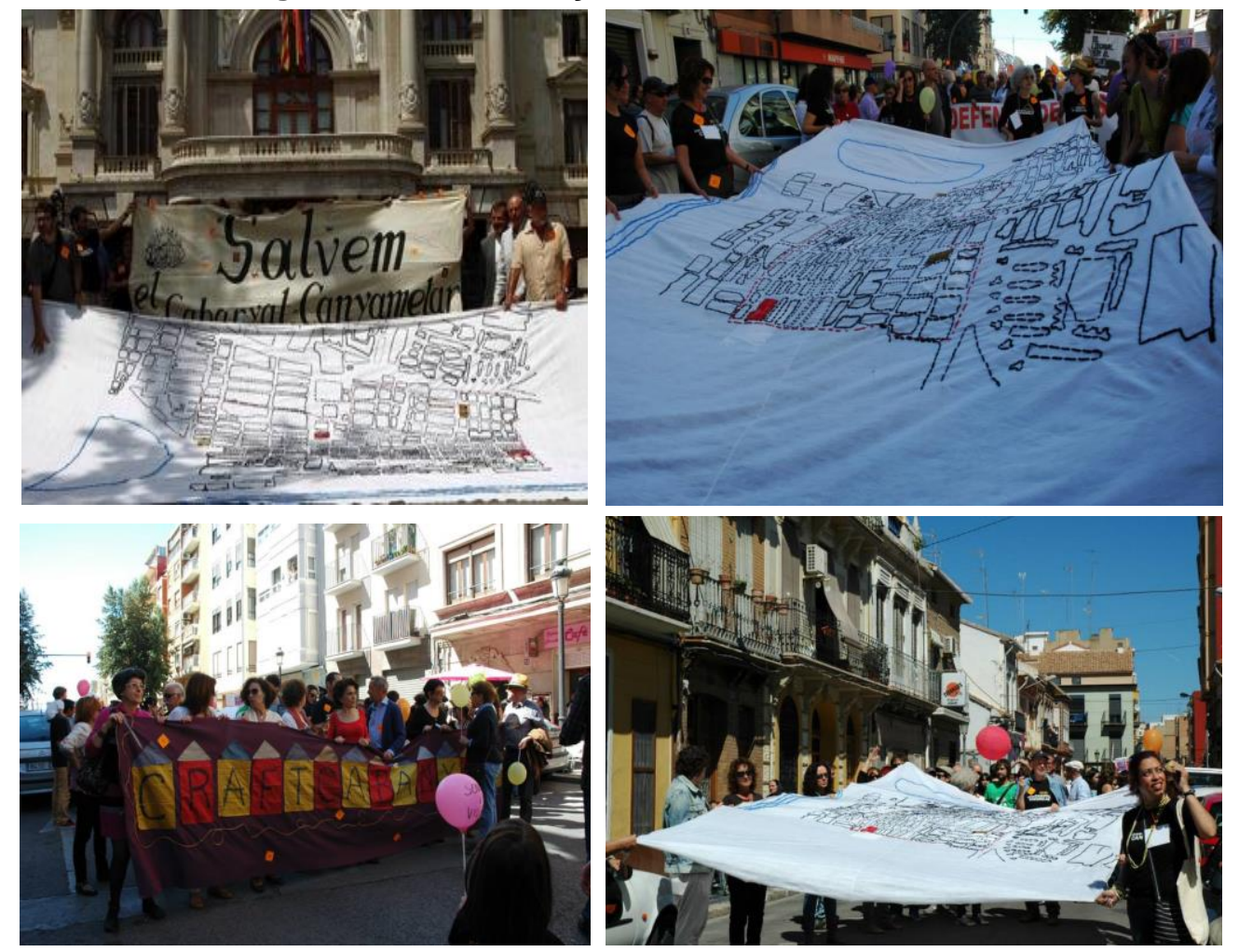

Fonte: Foto de arquivo do projeto CraftCabanyal in: http://www.espai214.org/craftcabanyalproyectos/

Figura 10 - Manifestações de 8 de março
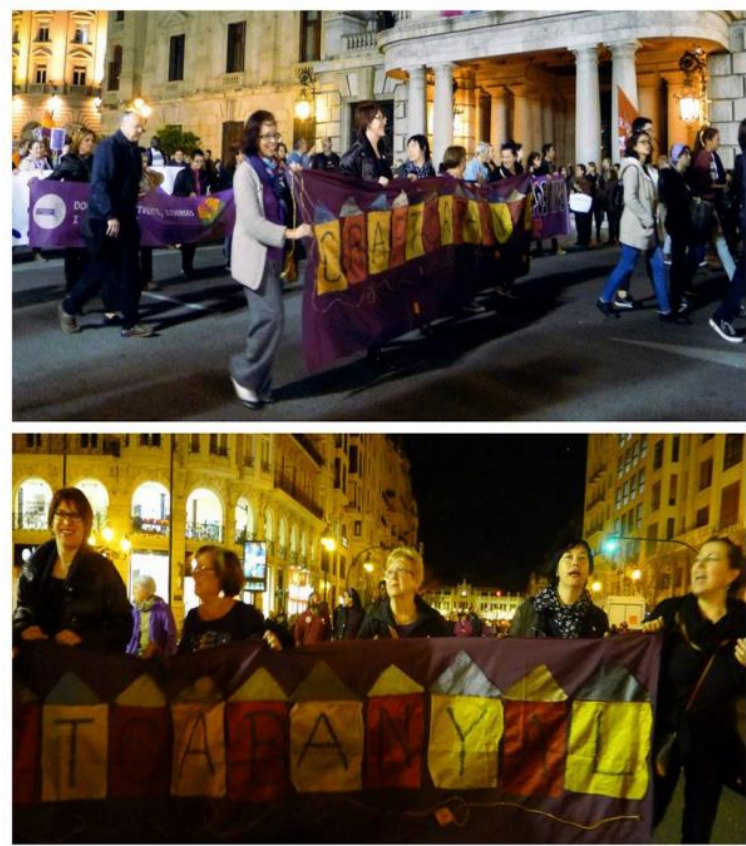

Fonte: Foto de arquivo do projeto CraftCabanyal in:

http://www.espai214.org/craftcabanyalproyectos/

SANTOS, Fabiane Cristina Silva dos. Projeto CraftCabanyal: ações participativas de craftivismo na construção de obras artísticas reivindicativas a partir da iconografia de um lugar.

Revista GEARTE, Porto Alegre, v. 8, n. 1, p. 154-169, jan./abr. 2021.

Disponível em: http://seer.ufrgs.br/gearte 


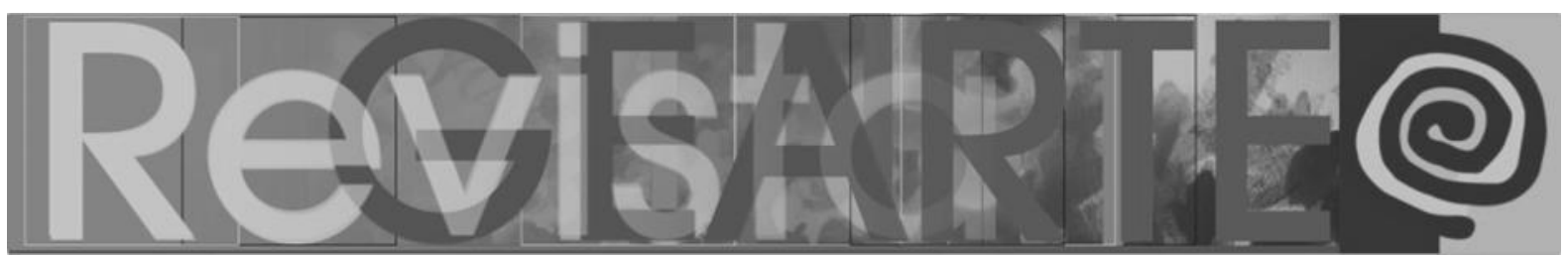

Concluímos que o processo artesanal se converteu em uma ferramenta para ações ativistas, e o Craftvismo cada vez mais se expande por diversos âmbitos sociais e conta com as novas tecnologias como apoio para a promoção das ações. Também vemos como a arte têxtil está se consolidando como expressão artística já que as atividades manuais, que durante muito tempo foram consideradas trabalhos domésticos a serem realizados na espera privada da casa, agora passam a ser ações públicas e coletivas, ganhando protagonismo no âmbito artístico e conquistando novos espaços e formas inéditas de relação com o espectador.

As propostas de Craftvismo realizadas no bairro do Cabanyal são iniciativas de arte participativa que ajudaram a divulgar um problema concreto, mas que, acima de tudo, procuraram demonstrar o valor do bairro, que não é somente patrimonial, mas é também imaterial por causa do seu valor humano, que deve ser preservado. Desenvolver uma obra colaborativa gera coesão social pois todos comungam o mesmo objetivo. E, ao mesmo tempo, está-se educando para o exercício da cidadania e trabalhando a autoestima dos participantes, que passam a ser protagonistas de suas causas e artífices de uma obra, tomando consciência de suas responsabilidades dentro da sociedade.

\section{Notas}

1 Cabanyal Portes Obertes es un evento multidisciplinar de arte contemporáneo en el que los vecinos del barrio ceden sus casas como contenedores culturales y las abren para que el público conozca la problemática del barrio desde el interior de sus casas, mostrando una forma de vivir como contrapunto de la visión partidista de las autoridades locales. Se trata de un proyecto de intervenciones artísticas que reivindica la rehabilitación del barrio de El Cabanyal, en Valencia, amenazado por un proyecto urbanístico. Con el cambio de gobierno en las últimas elecciones de 2015 el proyecto fue derogado.

2 Cf. http://craftcabanyal.espai214.org/ (2013).

3 Coletivo cidadão de defesa e conscientização pública sobre esta situação e, por extensão, sobre a gestão de todo o patrimônio histórico, nascido em 1998 no bairro de Cabanyal, em Valência, com o objetivo de evitar o prolongamento da avenida Blasco Ibáñez, que significaria demolir 1.651 casas, projeto paralisado com a mudança de governo em 2015 e a respectiva revogação do plano. Cf. http://www.cabanyal.com/ (2013). 


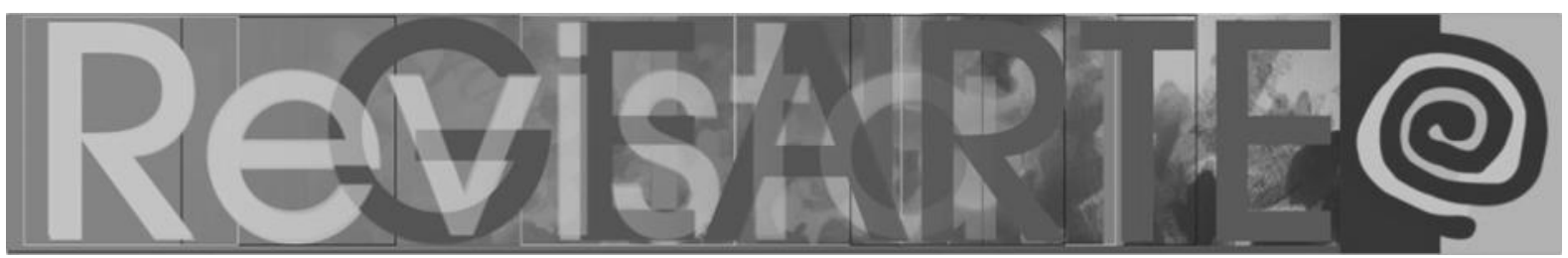

\section{Referências}

BLANCO, Paloma. Prácticas artísticas colaborativas en la España de los años noventa. Desacuerdos sobre arte, políticas y esfera pública en el Estado español, [s. I.], n. 2, p. 188-205, 1989. Disponível em: http://ayp.unia.es/dmdocuments/des_c02.pdf. Acesso em: 17 abr. 2014.

CRAFTCABANYAL. Proyectos. CraftCabanyal, València, 2013. Disponível em: http://craftcabanyal.espai214.org/. Acesso em: 9 mar. 2017.

CROCHET CORAL REEF. Project. Crochet Coral Reef, Los Angeles, 2020. Disponível em: http://crochetcoralreef.org/satellite/chicago.php. Acesso em: 14 mar. 2017.

DUQUE, Félix. Arte público y espacio político. Madrid: Akal, 2001.

ECHEVERRÍA, María Clara. Hábitat vs vivienda: mirada crítica al viviendismo. In: LA CONSTRUCCIÓN DEL HÁBITAT POPULAR: EXPERIENCIAS DE INTERVENCIONES URBANAS, ARQUITECTÓNICAS, TECNOLÓGICAS, Y PEDAGÓGICAS, 1., 2003, Bogotá. Anais [...]. Bogotá: Universidad la Gran Colombia, 2003.

GARRIDO, Alfredo P. El arte comunitario: origen y evolución de las prácticas artísticas colaborativas. Arteterapia, Madrid, v. 4, p. 197-211, 2009. Disponível em: https://revistas.ucm.es/i ndex.php/ARTE/article/view/9641. Acesso em: 4 maio 2015.

LIPPARD, Lucy R. Mirando alrededor: dónde estamos y dónde podríamos estar: modos de hacer. Arte crítico, esfera pública y acción directa. Salamanca: Ediciones Universidad de Salamanca, 2001.

MARTÍNEZ, Emilio; SILVA DOS SANTOS, Fabiane. Una herramienta de resistencia: Cabanyal Archivo Vivo: el archivo digital como estrategia de resistencia frente a las inercias urbanísticas de destrucción del patrimonio. In: CONGRESO INTERNACIONAL DE EDUCACIÓN PATRIMONIAL, 2., 2014, Madrid. Actas [...]. Madrid: IPCE: OEPE, 2014. p. 689-702.

MORRIS, William. Arte y sociedad industrial. Valencia: Fernando Torres Editor, 1977.

RANCIÈRE, Jacques. El espectador emancipado. Buenos Aires: Manantial, 2010.

SALVEM EL CABANYAL. Historia. Salvem el Cabanyal, València, 2020. Disponível em: http://www.cabanyal.com/. Acesso em: 9 mar. 2017.

SENNETT. Richard. Artesanía, tecnología y nuevas formas de trabajo. Barcelona: Katz Editores, 2013.

SILVA DOS SANTOS, Fabiane. Mujer, casa y nuevos medios: el arte de tejer en red, una propuesta experimental artística neomedial. 2015. Tesis (Doctorado en Artes Visuales) - Universitat Politècnica de València, València, 2015. Disponível em: http://hdl.handle.net/10251/58774. Acesso em: 9 mar. 2017.

SILVA DOS SANTOS, Fabiane El arte participativo, acciones reivindicativas y colaborativas que buscan la cohesión social: de lo local a lo global. In: CONGRESO INTERNACIONAL DE INVESTIGACIÓN EN ARTES VISUALES, 3., 2017, València. Actas [...]. València: ANIAV, 2017 Disponível em: http://dx.doi.org/10.4995/ANIAV.2017.6340. Acesso em: 17 mar. 2019.

URBAN KNITTING BARCELONA. Home. Urban Knitting Barcelona, Barcelona, 2014. Disponível em: http://urbanknittingbarcelona.blogspot.com.es/. Acesso em: 12 mar. 2017. 


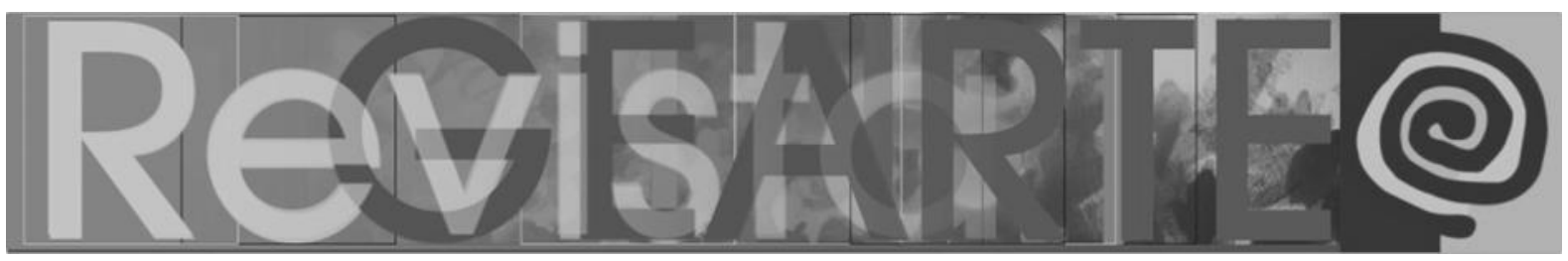

\section{Fabiane Cristina Silva dos Santos}

Doutorado em Artes Visuais e Intermedia pela Universidad Politécnica de Valência, Espanha. Possui graduação em Artes Plásticas pela Universidade Federal da Bahia (1997), mestrado em Artes Visuais e Intermedia - Universidad Politécnica de Valência (2010), mestrado em Artes Visuais pela Universidade Federal da Bahia (2002), especialização em Metodologia do Ensino Superior e em Artes Visuais e intermidias. Tem experiência na área de artes, com ênfase em artes plásticas, atuando principalmente nos seguintes temas: universo feminino, instalação, poéticas tecnológicas, arte participativo, gênero. Realiza diferentes atividades independentes no âmbito da arte e sua difusão. Desenvolve pesquisa relacionada ao universo feminino e suas relações com o espaço público e privado. Coordena o projeto de arte participativa com perspectiva de gênero CraftCabanyal (ES), colaborou no projeto de arte público Cabanyal Portes Obertes (ES) 2005-2014. Coordenou o Projeto Cabanyal Archivo Vivo, prêmio Europa Nostra na categoria Educação, formação e sensibilidade no ano de 2011.

ORCID: https://orcid.org/0000-0003-1200-8598

E-mail: biasantos13@gmail.com

Currículo: http://biasantos.espai214.org/

Recebido em 29 de maio de 2020 Aceito em 12 de outubro de 2020 